\title{
Two Arteriovenosus Fistulas Arising from Circumflex Artery (Cx) and Right Coronary Artery (RCA) to Pulmonary Artery and Coil Embolization of Cx Fistula
}

\author{
Casit Olgun Celik ${ }^{*}$ and Orcun Ciftci \\ Department of Cardiology, Ankara Baskent University Hospital, Cankaya, Turkey \\ *Corresponding author: Casit Olgun Celik, Department of Cardiology, Ankara Baskent University Hospital, Cankaya, Turkey, Tel: +90 3122126868 E-mail: \\ drolgunclk09@gmail.com
}

Received date: September 27, 2014; Accepted date: October 17, 2014; Published date: October 24, 2014

Copyright: (C) 2014 Celik CO, et al. This is an open-access article distributed under the terms of the Creative Commons Attribution License, which permits unrestricted use, distribution, and reproduction in any medium, provided the original author and source are credited.

\begin{abstract}
Coronary artery anomalies are diagnosed coincidentally during conventional coronary angiography or autopsy, although coronary anomalies are the second common cause of the sudden cardiac death in young persons. They are usually benign and they rarely cause signs and symptoms. Some of them comprise arteriovenosus (AV) fistula arising from coronary arteries to the pulmonary artery. AV fistulae arising from a coronary artery to pulmonary artery are rarely encountered but two AV fistulae (CAF) arising from two separate coronary arteries are even rarer, only a few cases having been reported so far. Herein, we present a 53-year-old male patient who was on the waiting list for renal transplantation. He had exercise-induced dyspnea and angina pectoris. The electrocardiogram showed negative $\mathrm{T}$ waves in leads V5 and V6. A stress exercise (treadmill) test was performed, which revealed ST-T wave changes confined to leads V5 and V6. Coronary angiography detected two arteriovenous fistulae arising from circumflex $(\mathrm{Cx})$ and right coronary arteries (RCA) to the pulmonary arteries. Right heart catheterization revealed a Qp/Qs ratio of 1:5 a PCWP of $13 \mathrm{~mm}-\mathrm{Hg}$, and a PVR of 0.2 Wood units. Coil embolization was carried out for the fistula from RCA to pulmonary artery in the first session, followed by normalization of right heart catheterization indices, leading to cancelling any intervention against the fistula in circumflex (Cx) artery.
\end{abstract}

\section{Key Words:}

Anomalies; Coronary arteries; Arteriovenosus fistula; Coil Embolization

\section{Case Report}

A 53-year-old male patient with chronic renal failure a renal transplant candidate was admitted to our hospital with dyspnea and angina during exercise. The electrocardiogram showed negative $\mathrm{T}$ waves and ST segment depressions in leads V5 and V6. He had risk factors of cardiovascular disease, including hypertension, smoking, and chronic renal failure. Echocardiography demonstrated mild systolic dysfunction (1/4 mitral regurgitation) with an ejection fraction of 50\%. An exercise stress (treadmill) test was performed and ST-T wave changes were observed in leads V5 and V6. Thus, a coronary angiography was performed, which showed normal left main, left anterior descending artery. However, two arteriovenosus fistulae from $\mathrm{Cx}$ and right coronary arteries (RCA) to the pulmonary arteries were observed (Figures 1a, 1b, 2a, 2b).

A right heart catheterization was performed and a mean pulmonary capillary wedge pressure (PCWP) of $13 \mathrm{~mm}-\mathrm{Hg}$, pulmonary vascular resistance (PVR) of 0.2 Wood units, and a Qp/Qs ratio of 1.5 were found. Coil embolization was carried out for the fistula from RCA to pulmonary artery in the first session, followed by normalization of right heart catheterization indices, leading to cancelling any intervention against the fistula in $\mathrm{Cx}$ artery (Figure $3 \mathrm{a}, 3 \mathrm{~b}$ ).

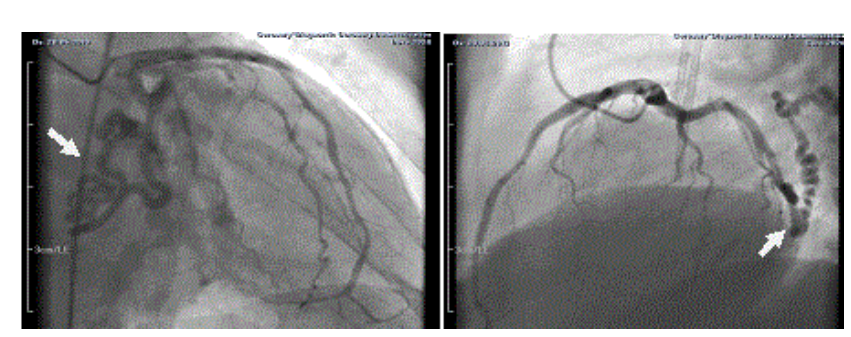

Figure 1a and 1b: AV fistulae originating from circumflex artery, anteroposterior caudal projectio (Figure 1a); left anterior oblique caudal projection (Figure 1b) (arrows). 
Citation: Celik CO, Ciftci O (2014) Two Arteriovenosus Fistulas Arising from Circumflex Artery (Cx) and Right Coronary Artery (RCA) to Pulmonary Artery and Coil Embolization of Cx Fistula. J Cardiovasc Dis Diagn 2: 182. doi:10.4172/2329-9517.1000182

Page 2 of 3
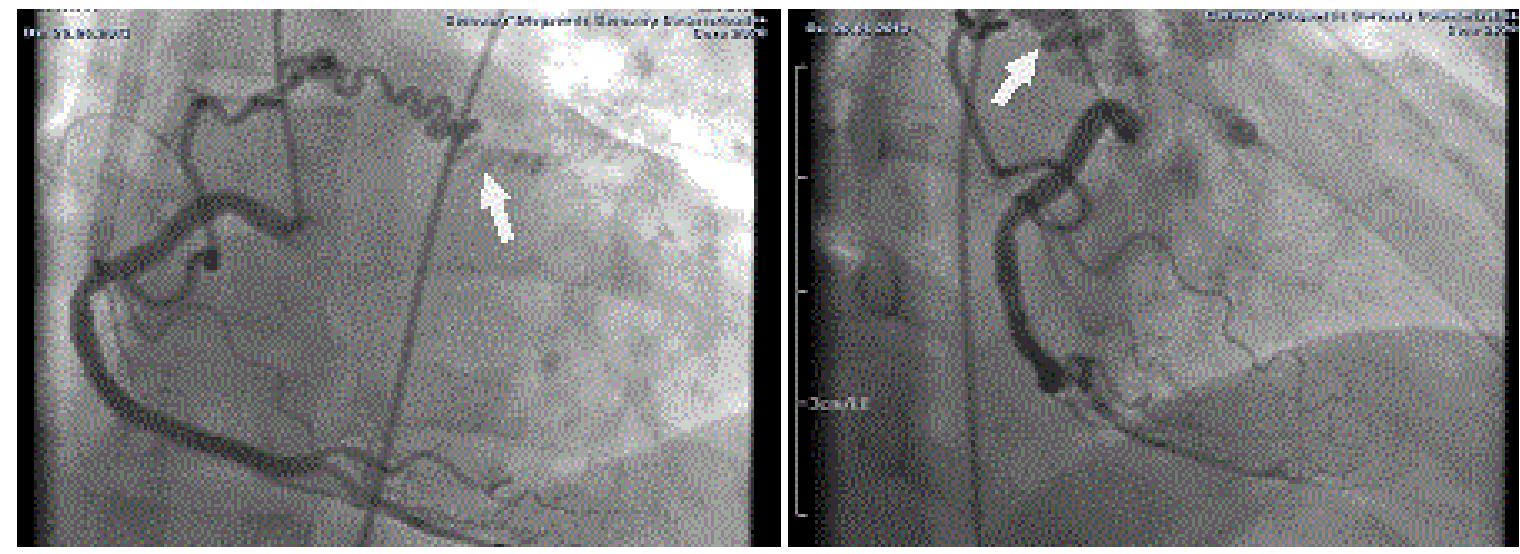

Figure 2a and $2 \mathrm{~b}$ : AV fistulae originating from right coronary artery, left anterior oblique cranial projection (Figure 2a); right anterior oblique straight projection (Figure 2b) (arrows).

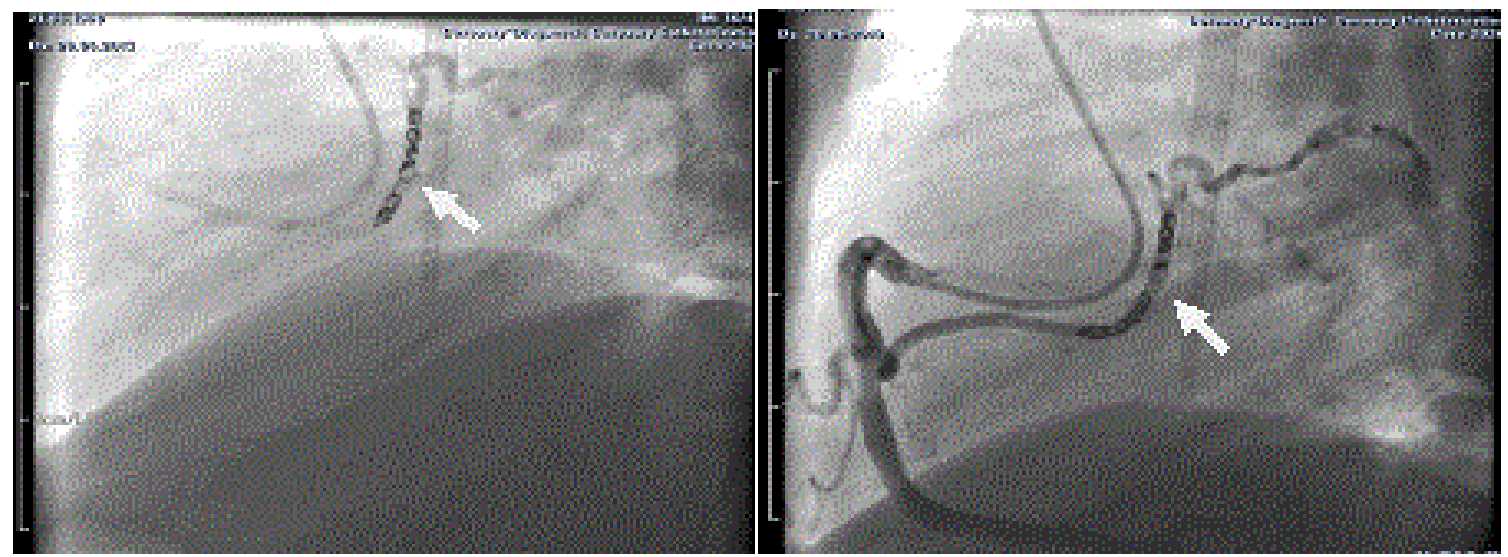

Figure 3a and 3b: Coil embolization of right coronary artery, left anterior oblique straight projection (arrows).

\section{Discussion}

Congenital anomalies of coronary arteries occur in $0.2-1.3 \%$ of the general population. Most of these anomalies are diagnosed coincidentally. Anatomically, coronary artery anomalies are of two major varieties: 1.origin and distribution anomalies and 2.coronary artery fistulae $[1,2]$. They constitute for $12 \%$ of all sports-related sudden cardiac deaths and $1.2 \%$ of non-sports-related deaths [3-5].

Coronary artery fistulae (CAF) are detected in $0.67 \%$ of all angiograms and are the most common coronary anomalies that require surgical repair [6]. Fistulae can be single or multiple and may originate and end in many vascular structures. However most fistulae originate from RCA and drain into a right-sided heart chamber [6].

Clinical manifestations of coronary artery fistulae include to left-toright shunting, myocardial ischemia secondary to coronary steal, sidebranch obstruction, mural thrombosis at sites of coronary ectasia, rupture at sites with aneurysmal wall degeneration, endocarditis, and aortic valvular insufficiency secondary to proximal coronary artery aneurysm. However, small fistulae, particularly those that drain into the main pulmonary artery and the left ventricle are usually benign. A pulmonary-systemic flow ratio greater than $1.5: 1$ is considered the primary surgical indication; aneurysmal degeneration, coronary rupture, or side-branch obstruction may also necessitate surgery [7]. The steal phenomenon associated with CAF may be persistent or episodic. Persistent steal can be caused by large fistulous tracts that also supply nutrient branches or receive collateral vessels that originate in the opposite coronary vessels; it can result in resting ischemia and hibernating myocardium. In contrast, episodic steal is related to physiologic factors increasing shunting through the fistula at the expense of nutrient flow. Unfortunately, ischemia may not be demonstrated by exercise and stress testing using vasodilators, since flow to the nutrient branches is likely to increase rather than the fistulous tract that usually lacks vasodilatory capacity. Moreover, nuclear stress tests usually fail to detect reversible ischemia, whereas a large coronary network may give rise to a false positive diagnosis of a myocardial scar. Invasive diagnostic modalities such as intravascular ultrasonography (IVUS) can be beneficial for detection of mural clots or aneurysms and pressure-wire measurements can be useful to determine pressure loss along coronary fistulae $[7,8]$.

A coronary arterial fistula is a connection between one or more coronary arteries and a cardiac chamber or great vessel. Although exact incidence is unknown, it is a rare defect that usually occurs in 
Citation: Celik CO, Ciftci O (2014) Two Arteriovenosus Fistulas Arising from Circumflex Artery (Cx) and Right Coronary Artery (RCA) to Pulmonary Artery and Coil Embolization of Cx Fistula. J Cardiovasc Dis Diagn 2: 182. doi:10.4172/2329-9517.1000182

Page 3 of 3

isolation [9]. It usually does not cause any symptoms or complications in the first two decades if small in size. After this age, however, the frequency of both symptoms and complications starts to increase $[10,11]$. Complications include 'steal' from the adjacent myocardium, thrombosis and embolism, cardiac failure, atrial fibrillation, rupture, endocarditis/endarteritis, and arrhythmias. Thrombosis within the fistula tract is a rare occurrence but may cause acute myocardial infarction, paroxysmal atrial fibrillation and ventricular arrhythmias. Spontaneous rupture of the aneurysmal fistula causing haemopericardium has also been reported [12-14]. The main differential diagnoses include patent ductus arteriosus, although other congenital arteriovenous shunts need also be considered in differential diagnosis. Although two-dimensional echocardiography may help differentiate coronary fistulae from other vascular anomalies, coronary angiography is the gold standard for determination of an anatomical abnormality. Surgery has traditionally been the treatment method of choice, although catheter closure using a variety of closure devices such as coils or other devices has recently been recommended [15]. With the catheter technique, the outcomes are excellent and the complication rate low. In our case, we detected two AV fistulae arising from Cx and RCA and successfully performed coil embolization to the AV fistula arising from RCA. Upon normalization of right heart catheterization indices, we cancelled coil embolization of the fistula that originated from $\mathrm{Cx}$.

\section{References}

1. Yamanaka O, Hobbs RE (1990) Coronary artery anomalies in 126,595 patients undergoing coronary arteriography. See comment in PubMed Commons below Cathet Cardiovasc Diagn 21: 28-40.

2. von Kodolitsch Y, Franzen O, Lund GK, Koschyk DH, Ito WD (2005) Coronary artery anomalies. Z Kardiol, 94: 1-13.

3. Angelini P (1989) Normal and anomalous coronary arteries: definitions and classification. See comment in PubMed Commons below Am Heart J 117: 418-434.

4. Burke AP, Farb A, Virmani R, Goodin J, Smialek JE (1991) Sports-related and non-sports-related sudden cardiac death in young adults. See comment in PubMed Commons below Am Heart J 121: 568-575.
5. Van Camp SP, Bloor CM, Mueller FO, Cantu RC, Olson HG (1995) Nontraumatic sports death in high school and college athletes. See comment in PubMed Commons below Med Sci Sports Exerc 27: 641-647.

6. Reul RM, Cooley DA, Hallman GL, Reul GJ (2002) Surgical treatment of coronary artery anomalies: report of a $371 / 2$-year experience at the Texas Heart Institute. See comment in PubMed Commons below Tex Heart Inst J 29: 299-307.

7. Angelini P, Velasco JA, Flamm S (2002) Coronary anomalies: incidence, pathophysiology, and clinical relevance. See comment in PubMed Commons below Circulation 105: 2449-2454

8. Angelini P (2002) Coronary artery anomalies--current clinical issues: definitions, classification, incidence, clinical relevance, and treatment guidelines. See comment in PubMed Commons below Tex Heart Inst J 29: 271-278.

9. Qureshi SA (2006) Coronary arterial fistulas. See comment in PubMed Commons below Orphanet J Rare Dis 1: 51.

10. Khan MD, Qureshi SA, Rosenthal E, Sharland GK (2003) Neonatal transcatheter occlusion of a large coronary artery fistula with Amplatzer duct occluder. See comment in PubMed Commons below Catheter Cardiovasc Interv 60: 282-286.

11. Oshiro K, Shimabukuro M, NakadaY, Chibana T, Yoshida H, Nagamine F et al. (1990) Multiple coronary LV fistulas: demonstration of coronary steal phenomenon by stress thallium scintigraphy and exercise haemodynamics. Am Heart J, 120: 217-219.

12. Skimming JW, Walls JT (1993) Congenital coronary artery fistula suggesting a "steal phenomenon" in a neonate. See comment in PubMed Commons below Pediatr Cardiol 14: 174-175.

13. Rämö OJ, Tötterman KJ, Harjula AL (1994) Thrombosed coronary artery fistula as a cause of paroxysmal atrial fibrillation and ventricular arrhythmia. See comment in PubMed Commons below Cardiovasc Surg 2: 720-722.

14. Bauer HH, Allmendinger PD, Flaherty J, Owlia D, Rossi MA, et al. (1996) Congenital coronary arteriovenous fistula: spontaneous rupture and cardiac tamponade. See comment in PubMed Commons below Ann Thorac Surg 62: 1521-1523.

15. Perry SB, Rome J, Keane JF, Baim DS, Lock JE (1992) Transcatheter closure of coronary artery fistulas. See comment in PubMed Commons below J Am Coll Cardiol 20: 205-209. 